\title{
TANTALUM THIN FILM APPLICATIONS - A NEW APPROACH FOR CAPACITORS
}

\author{
A. PERINATI \\ Telettra S.p.A. 20059 Vimercate, Milano, Italy
}

(Received May 1, 1977)

\begin{abstract}
Tantalum-based materials and process developments have increased the use of tantalum films, combined with silicon integrated circuits, to form hybrid integrated circuits which can meet the demands of telecommunication systems. This paper, after a historical review, describes the status of tantalum thin film technology used at Telettra in the implementation of circuits for telecommunication equipment. In particular, this paper focusses on the efforts devoted to the improvement of the $\beta$-Ta capacitor process in terms of yield and reliability for $R C$ active filter realization. The results of a new $\mathrm{Ta}_{2} \mathrm{O}_{5}-\beta$ Ta deposition process, where a $\mathrm{Ta}_{2} \mathrm{O}_{5}$ layer is first formed by d.c. reactive sputtering in oxygen in the same vacuum batch where the $\beta$-Ta film is sequentially formed, are given.
\end{abstract}

\section{INTRODUCTION}

Twenty years after the first investigations of thin film materials used in microelectronics, thin film technology has reached a remarkable stage of development and application especially in telecommunication.

The basic reason is to be found in the complementary characteristic of thin film technology with respect to semiconductor integrated circuits. Thin film technology has limited applications in the field of active components, typical of semiconductor technology, but it is suitable for implementing resistors and capacitors with peculiar characteristic, range of values, temperature coefficients, stability etc., which would not be easy to achieve with semiconductor integrated circuit technology. The first ten years of thin film technology have been characterized by the study of film properties and by the implementation of discrete components; in the following ten year period the development of applications has taken over the outcome of which being circuits having several $\mathrm{R}$ and $\mathrm{C}$ components on one substrate and, in general, hybrid circuits of remarkable complexity.

In the last few years efforts have been orientated towards the improvement of industrial processes as well as towards cost reduction as a consequence of the trend in international economy; for example, the degree of miniaturization in hybrid integrated circuits has increased and the use of highly priced metals has been limited.

If the $\mathrm{NiCr}$ and $\mathrm{Ta}$ technologies are considered, and the:e represent the trend followed by the majority of manufacturers in the field of thin film hybrids, the following can be observed.

From early studies on $\mathrm{Cr},{ }^{1}$ as thin film material for resistors because of its high vapour tension and resistivity, and on $\mathrm{NiCr}$ because of the property of resistivity and temperature coefficient of such thin film alloy, ${ }^{2,3}$ new deposition techniques have developed together with improved processes which have led to new $\mathrm{NiCr}$ thin film resistors with repeatable electrical characteristics and low temperature coefficient as required in professional circuits. Ta technology has developed essentially from the "Bell Labs" where Basseches ${ }^{4}$ obtained in 1957 the first resistive film of Ta by means of cathode sputtering. In the same year Berry ${ }^{5,6}$ began research on the technology which eventually led to the invention of Ta thin film capacitor. From then on a vast research and development program was carried on in the Bell Labs and in other research institutions in the USA, Japan, Europe, etc.

As a result of studies on the effect of such elements as $\mathrm{N}, \mathrm{C}, \mathrm{O}$ on the structure and electrical properties of films as resistors, the development of Tantalum Nitride, ${ }^{7}$ as the most suitable film for resistors, took place due to its characteristics of resistivity, temperature coefficient, stability etc. A deeper knowledge of sputtering techniques led to the development of "Low Density Ta" for high resistivity films. ${ }^{8}$ Films deposited with $\mathrm{N}_{2}$ and $\mathrm{O}_{2}$ reactive sputtering led to simultaneous implementation of RC groups temperature compensated by virtue of variation of the film TCR in such a way as 
to balance out the capacitor coefficient (TCC). ${ }^{9}$

The research on RC integrated networks led to the development of Ta-Al alloy films which provides high value resistors with high stability and low TCR. ${ }^{10,11}$ As for Ta thin film capacitors their TM structure is at the basis of a high degree of accuracy, stability, of repetitive TCC and dissipation factor which makes them suitable for active RC hybrid integrated circuits. Moreover, the need of miniaturizing, hence of increasing the sheet capacitance, has led to the development of the TMM ${ }^{12}$ structure where, thanks to selfhealing properties of materials such as manganese dioxide, and lead dioxide, the influence of the drawbacks of tantalum pentoxide have been balanced out, especially for small dielectric thickness.

The study on the $\mathrm{N}, \mathrm{C}, \mathrm{O}$ effect on Ta, with respect to stability has brought to capacitors high quality in terms of leakage current, yield, breakdown voltage, realized with $\beta$-Ta $\mathrm{N}_{2}$ doped films. ${ }^{13}$ Also, the behaviour at high temperature of capacitor TCC, dissipation factor, capacitance variation etc. has been optimized. ${ }^{14}$ Besides a presentation of the state of Ta thin film technology in Telettra, the present work reports some results obtained in the first production exercise of $\beta$-Ta capacitors used in the implementation of RC active filters; it also describes the efforts produced towards the improvement of the fabrication process in terms of yield and reliability.

In particular, the deposition process of $\mathrm{Ta}_{2} \mathrm{O}_{5}-\beta$ Ta films is described where a tantalum pentoxide layer is first formed by d.c. reactive sputtering in oxygen in the same vacuum batch where the $\beta$-Ta film is sequentially formed.

\section{STATUS OF RESISTOR AND CAPACITOR PROCESSES IN TELETTRA}

Ta thin film technology has been used at Telettra in the implementation of circuits for telecommunication equipment for about 10 years. Resistors are realized both with tantalum nitride films and tantalum oxynitride films depending on the required characteristics. Capacitors mostly make use of structures made of $\beta \mathrm{Ta}-\mathrm{Ta}_{2} \mathrm{O}_{5}-\mathrm{NiCr}+\mathrm{Au}$; the interdigitated structure is also used in some applications.

\section{$2.1 \quad$ Resistors}

Tantalum nitride resistors are adopted in digital, analog, and microwave circuits. Film deposition is by means of reactive sputtering on both glazed and unglazed alumina substrates, with $50 \Omega /$ sq. sheet resistance.

Tantalum oxynitride resistors are used for temperature compensated $\mathrm{RC}$ active filters. They are deposited by means of reactive sputtering with $100 \Omega /$ sq. sheet resistance and feature about $-200 \mathrm{ppm} /{ }^{\circ} \mathrm{C}$ TCR which balances out the TCC of the capacitor. Sequence $\mathrm{NiCr}, \mathrm{Au}$, as well as $\mathrm{Ti}, \mathrm{Pd}$, $\mathrm{Au}$ is used for conductors; the latter is used in hybrid

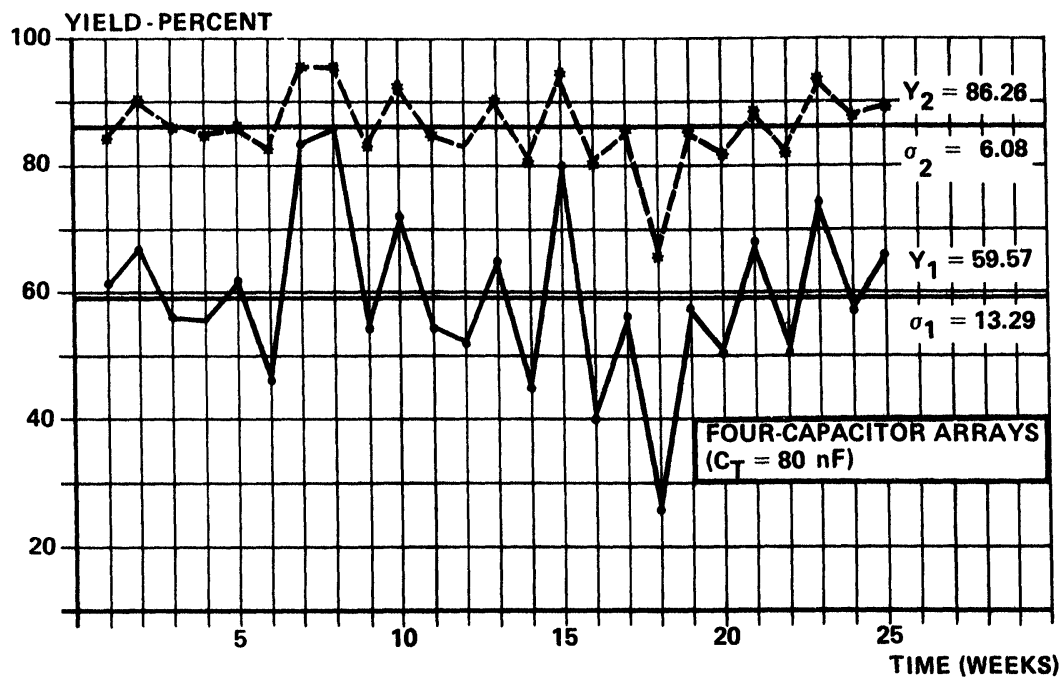

FIGURE 1 Yield of Ta thin film capacitors in pilot production. $50 \mathrm{~V}, 125^{\circ} \mathrm{C}, 30$ minutes test. 
circuits with beam leaded active components where, as a general rule, the working or process temperature is high.

As for microwave circuits the microstrip thickness is increased with an electrochemical process up to a few micron. For the adjustment of resistors to their final value, the anodizing process is used. Equipment has been produced in which all resistors contained in one 2 " $\times 2$ " substrate may be anodized in a few seconds. Circuit scribing is obtained with a $\mathrm{CO}_{2}$ laser system featuring $100 \mathrm{Wcw}$ output power.

\subsection{Capacitors}

Ta thin film capacitors are produced using standard overlap, interdigitated and bipolar interdigitated designs to meet the required circuit characteristic

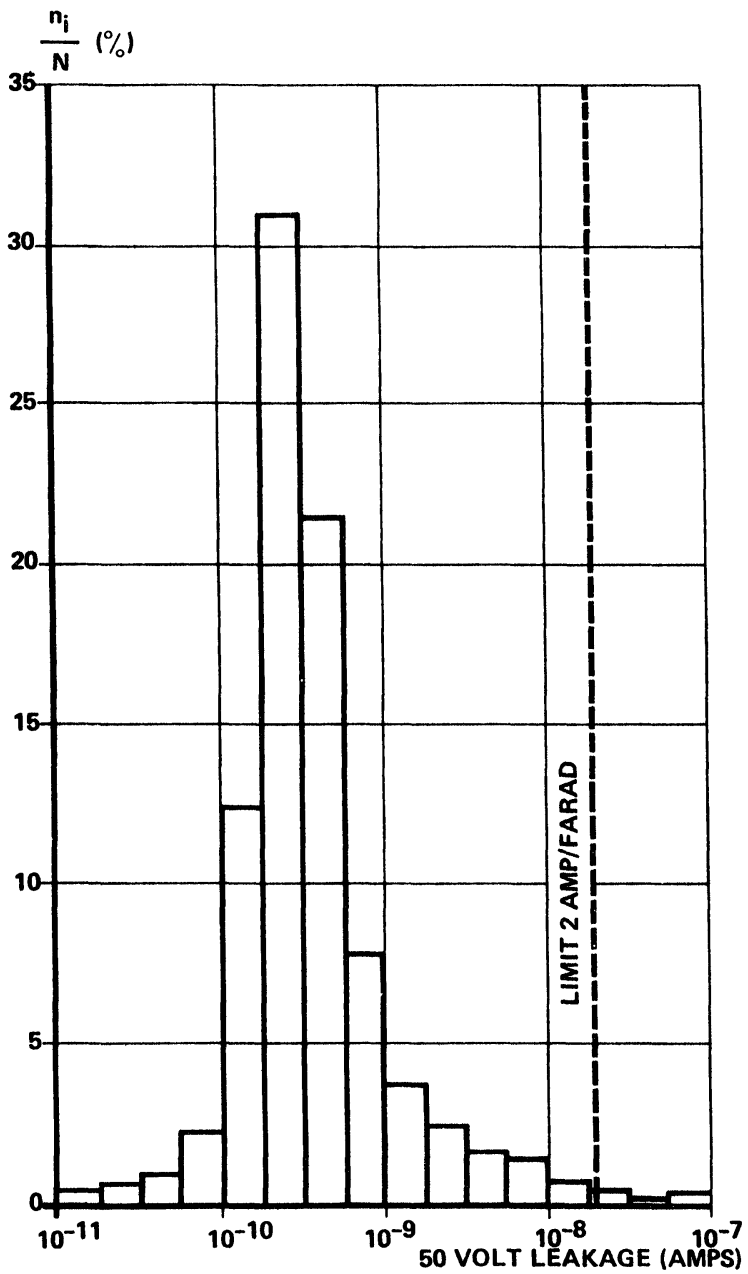

FIGURE 2 Leakage current distribution of $0.36 \mathrm{~cm}^{2}$ Ta-film capacitors formed at $230 \mathrm{~V}$.
TABLE I

Comparison of original and new processes for deposition of $\mathrm{Ta}_{2} \mathrm{O}_{5}-\beta \mathrm{Ta}$ layers

\begin{tabular}{ll}
\hline Original process steps & New process steps \\
\hline Substrate cleaning & Substrate cleaning \\
Sputter $\beta$-Ta film & Sputter $\mathrm{Ta}_{2} \mathrm{O}_{5}-\beta \mathrm{Ta}$ films \\
Thermally oxidize $\beta$-Ta film & \\
Substrate cleaning & \\
Sputter $\beta$-Ta film & \\
\hline
\end{tabular}

such as capacitance values, dissipation factor etc. The standard TM structure is primarily used for the production of $\mathrm{RC}$ active filters temperature compensated with tantalum oxynitride resistors.

$\beta$-Ta films are sputtered on glazed alumina substrates to a thickness of about $4000 \AA$. A tantalum pentoxide layer is used to protect the glazed substrate from subsequent hydrofluoric acid etchants. The tantalum oxide dielectric is produced by a conventional process using anodic oxidation at room temperature in $0.01 \%$ aqueous citric acid electrolyte, at a current density of $0.3 \times 10^{-3} \mathrm{~A} / \mathrm{cm}^{2}$ Formation voltage of $230 \mathrm{~V}$ and soak time of $1 \mathrm{~h}$ are used. Nichrome-gold counterelectrodes, about $2000 \AA$ thick are evaporated using filament evaporation sources. Equipment has been developed to control capacitance value and dissipation factor and to make a screening test at $50 \mathrm{~V}$ for 1 minute of capacitors arrays by on-line computer, for high production rates.

\section{A NEW APPROACH FOR CAPACITOR PRODUCTION}

Production of Ta thin film capacitors is likely to be affected by yield problems, especially for high capacitor values.

Figure 1 shows the results of a pilot production line of a batch of $3500 \mathrm{Ta}$ film capacitor networks with $56 \mathrm{nF} / \mathrm{cm}^{2}$ sheet capacitance, made up of four equal capacitors for a total of $80 \mathrm{nF}$. Data are referred to a condition whereby arrays can stand a screening test of 50 volts at $125^{\circ} \mathrm{C}$ for 30 minutes without catastrophic breakdown. The same figure shows yield results of the single $20 \mathrm{nF}$ capacitor as an array component. Data show in terms of yield the price necessary to realize high value capacitors.

The average yield value drops from about $85 \%$ to about $60 \%$ when the capacitor value rises from $20 \mathrm{nF}$ to $80 \mathrm{nF}$, in the condition of $50 \mathrm{~V}, 125^{\circ} \mathrm{C}$ for 30 minutes. Process control has indicated the factors 
TABLE II

Economic advantages of $\mathrm{Ta}_{2} \mathrm{O}_{5}-\beta \mathrm{Ta}$ sequential deposition using a bell jar batch system

\begin{tabular}{ll}
\hline Cycle-time reduction & $40 \%$ \\
Yield increase & $10 \%$ \\
Thin film capacitor cost reduction & $15 \%$ \\
\hline
\end{tabular}

responsible for the large yield variation among batches of capacitors; these factors are often superficial irregularities of the glazed substrates or caused by handling, and impurities left over after cleaning processes, especially at interfaces between $\mathrm{Ta}-\mathrm{Ta}_{2} \mathrm{O}_{5}$, $\mathrm{Ta}_{2} \mathrm{O}_{5}-\mathrm{NiCr}+\mathrm{Au}$. In order to improve yield and reliability efforts have been concentrated towards the reduction of the above mentioned factors by means of modifications in the fabrication process.

In particular, the process of $\mathrm{Ta}_{2} \mathrm{O}_{5}-\beta \mathrm{Ta}$ film deposition has been simplified by means of sequential deposition within the same vacuum cycle. Also a thick layer of photoresist material has been used, deposited immediately after the definition of counterelectrode geometry, in order to protect the capacitors during the operation of testing, scribing, snapping, soldering etc. The layer is removed just before the final encapsulation.

In the new process a tantalum pentoxide layer, used to protect the glazed substrate from subsequent hydrofluoric acid etchants is formed by d.c. reactive sputtering in oxygen in the same vacuum batch where $\beta$-Ta film, about $4000 \AA$ thick, is sequentially formed by d.c. sputtering.

A comparison of the original and new processes is shown in Table I. In regard to time and cost reductions and to yield increase, some process-steps and non productive time of the sputtering cycle have been eliminated. The results, using a $71 \mathrm{~cm}$ commercially available diffusion pumped vacuum system, are given in Table II. Sheet resistance, resistivity and TCR values of $\beta$-Ta films, formed by d.c. sputtering on glazed substrates using the new $\mathrm{Ta}_{2} \mathrm{O}_{5}-\beta \mathrm{Ta}$ deposition process, are reported in Table III.

An oxygen doped Ta layer, about $500 \AA$ thick is formed at the $\mathrm{Ta}_{2} \mathrm{O}_{5}-\beta \mathrm{Ta}$ interface as shown by TCR behaviour with film thickness. The capacitors properties are similar to those obtained from a standard process. The $50 \mathrm{~V}, \mathrm{R} . \mathrm{T}$., leakage current distribution of $20 \mathrm{nF}$ capacitors, evaluated on about 5,000 samples, is shown in Figure 2. Data of aging test at different voltage-temperature values show a good behaviour of capacitors formed in this manner, with respect to the original process and related reliability.

\section{SUMMARY AND CONCLUSIONS}

Tantalum-based materials and process developments have increased the use of tantalum films, combined with silicon integrated circuits, to form hybrid integrated circuits which can meet the demands of telecommunication systems. The RC active networks temperature compensated using resistor-capacitor technology on a single substrate, is one major application of tantalum thin film technology. In the past few years the search for greater economies has led to circuit miniaturization and to replacement of precious metals for less costly circuit metalizations. In order to improve the capacitor yield and reliability for $\mathrm{RC}$ active filters, temperature compensated in the production of Telettra telecommunication. systems, a new process has been developed for depositing $\mathrm{Ta}_{2} \mathrm{O}_{5}-\beta \mathrm{Ta}$ films by sputtering. In this process a $\mathrm{Ta}_{2} \mathrm{O}_{5}$ layer, used to protect the glazed

TABLE III

Sheet resistance, resistivity and TCR of $\beta$-Ta films sequentially deposited on to reactive sputtered $\mathrm{Ta}_{2} \mathrm{O}_{5}$

\begin{tabular}{llll}
\hline Runs & $\mathrm{R} / \mathrm{sq} .(\Omega / \mathrm{sq})$. & $\rho(\mu \Omega \cdot \mathrm{cm})$ & $\begin{array}{l}\text { TCR }\left(\mathrm{ppm} /{ }^{\circ} \mathrm{C}\right) \\
\left(-196^{\circ} \mathrm{C} \text { to } 25^{\circ} \mathrm{C}\right)\end{array}$ \\
\hline 1 & 4.5 & 209 & -146 \\
2 & 4.8 & 213 & -134 \\
3 & 4.7 & 209 & -132 \\
4 & 4.7 & 208 & -128 \\
5 & 4.4 & 200 & -105 \\
6 & 4.6 & 204 & -114 \\
7 & 4.7 & 207 & -132 \\
8 & 4.7 & 212 & -140 \\
9 & 4.7 & 210 & -130 \\
10 & 4.5 & 201 & -100 \\
\hline
\end{tabular}


substrate from subsequent hydrofluoric acid etchants, is first formed by d.c. reactive sputtering in oxygen in the same vacuum batch where $\beta$-Ta film is sequentially formed. The processing innovation has proven to be valuable for capacitor production, resulting in economy of labor in handling, processing and in increased yield. The initial properties as well as the long term behaviour of capacitors formed in this manner are typical of a standard capacitor process.

\section{REFERENCES}

1. C. T. Graham, Proc. of the 1952 Electronic Components Conference of the IRE-AIEE, pp. 61-63.

2. R. H. Alderson and F. Ashworth, Brit. J. App. Phys., 8, (1957) 205.
3. J. G. Swanson and D. S. Campbell, Thin Solid Films, 1, (1967) 183.

4. Bell Lab. Rec., 36, (1958) 426.

5. R. W. Berry and D. Sloan, Proc. IRE, 47, (1959) 1070.

6. R. W. Berry, U.S.P., 2, 993, 266, dated July 25, 1961.

7. D. Gerstenberg and E. H. Mayer, Proc. Electronic Components Conference, Washington, D.C., 1962, p. 57.

8. H. J. Schuetze, H. W. Ehlbeck and C. G. Doerbeck, A. V. S. 1963 Trans. 10th Natl. Vac. Symp., Macmillan Co., New York, 1963, p. 434.

9. G. I. Parisi, Proc. Electronic Components Conference, Washington, D.C., 1969, p. 367.

10. C. A. Steidel, J. Vac. Sci. Technol., 6, (1969) 694.

11. A. Schauer and M. Roschy, Proc. Electronic Components Conference, Washington, D.C., 1973, p. 245.

12. D. A. McLean and F. E. Rosztoczy, Electrochem. Technol., 4, (1966) 523.

13. H. Y. Kumagai, I. M. Fletcher, K. R. Bauerle, J. R. Hightower and C. A. Steidel, Proc. Electronic Components Conference, Washington, D.C., 1973 p. 257.

14. W. Anders, Thin Solid Films, 27, (1975) 135. 

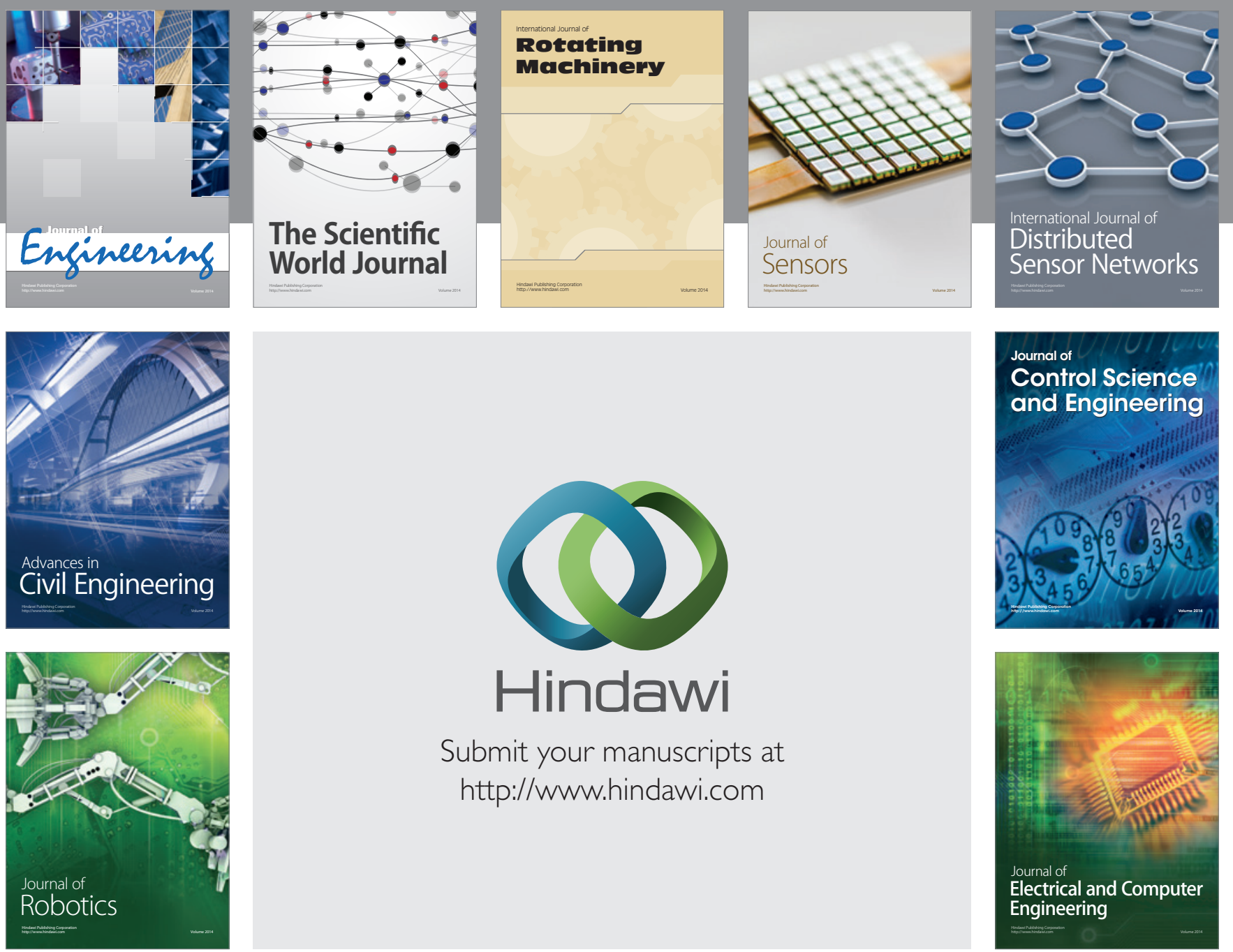

Submit your manuscripts at

http://www.hindawi.com
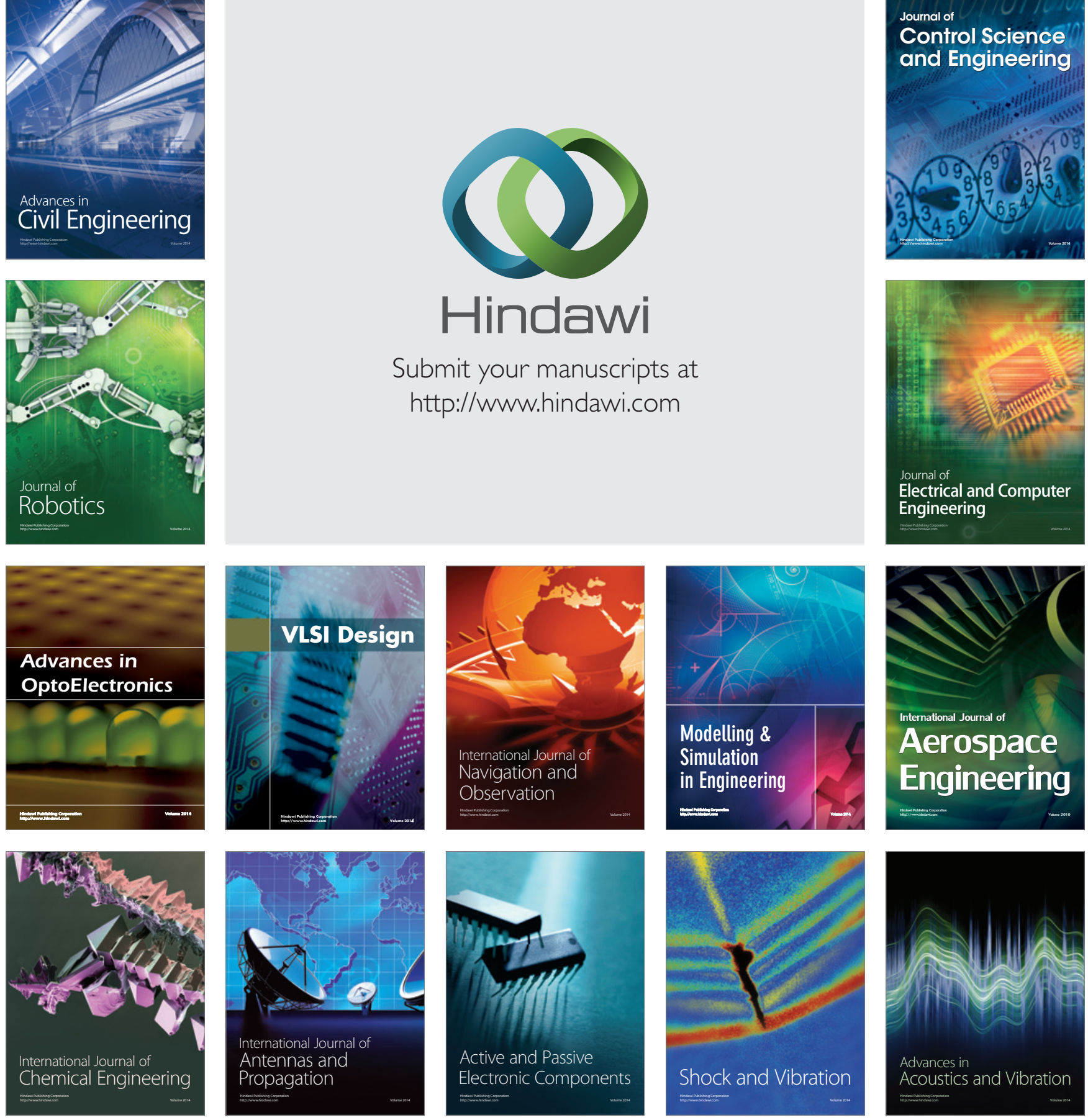